\title{
Interrelation Structures - EDI of Regional Innovation System of local area. A Systemic Approach
}

\section{Estructuras de interrelación - EDI del Sistema Regional de Innovación de área local. Un Enfoque Sistémico}

\author{
C. Medina ${ }^{1}$, E. Buelvas², C. Henriquez \\ ${ }^{\prime}$ M.Sc., Facultad de Ingeniería, Universidad de la Costa, Grupo de Investigación Producom, Barranquilla, Colombia. cmedina4@cuc.edu.co \\ ${ }^{2}$ PH.D., Facultad de Ingeniería, Universidad Autónoma del Caribe, Grupo de Investigación sistemas inteligentes y muevas tecnologías, \\ Barranquilla,Colombia,Edgardo.buelvas@uac.edu.co \\ ${ }^{3}$ PH.D., Facultad de Ingeniería, Universidad Autónoma del Caribe, Grupo de Investigación sistemas inteligentes y muevas tecnologías, \\ Barranquilla, Colombia, Carlos.henriquez@uac.edu.co
}

Cite this article as: C. Medina, E. Buelvas, C. HEnriquez "Interrelation Structures - EDI of Regional Innovation System of local area. A Systemic Approach", Prospectiva, Vol 18, No 1, 40-50, 2020.

Recibido: 21/01/2020 / Aceptado: 21/02/2020

https://doi.org/10.15665/rp.v18i1.2253

\begin{abstract}
This paper presents an analysis of the interactivity of the Regional Innovation System - SRI case of Atlantic department, with the intention of raising some guidelines within said SRI, which encourage interactivity in the activities of development cooperation endogenous technological. This proposal adopts the Structures of Interaction - EDI, to mean interactions in the scientific environment of the Atlantic department in Colombia, aimed at boosting the analysis of university-business relationship under a systemic approach. To this end, questionnaires, log sheets on project data, observation and interview participants of cooperation and collaboration projects beginning itself to document the result of the targets were used. The first results have a greater weight on the lines of generation of knowledge to the company and academia, predominantly through the training of human resources. Second, the results are expressed in improving processes, which sometimes lead to technical improvements in production processes for companies, but in very low proportion in the improvement of products; and to a much lesser extent radical innovations or results generated in response to the solution of social problems or in response to government policies.
\end{abstract}

Key words: Interaction Structures, Regional Innovation System, Systemic Approach.

\section{INTRODUCTION}

Given the conceptual evolution of the national innovation systems [1], the first authors appreciations are collected [2], these authors are the most recognized for really establishing what an innovation system consists of, classifying them into national and regional [3] and also takes a tour of the characteristics of regional innovation systems [4]. However, for the purposes of this investigation, all the characteristics and elements necessary to perform the analysis of the local Regional Innovation System -SRI [5], in the case of the department of Atlántico, are established.

In addition, it was part of the adaptation of the innovation systems model of Fernández de Lucio and Castro, cited by
Monroy [6], who explains the System of Science, Technology and Innovation from the types of actors that make it up: technological subsystem, scientific, financial, productive and facilitator, a process that is achieved by differentiating their functions and recognizing integration and interaction between them.

An interrelation structure - EDI, is a unit established in an environment or in its area of influence to dynamize, in terms of technological innovation, the elements of said environment or others, and foster and catalyze the relationships between them [1]. However, the systemic approach is strongly present in the analysis of the system [7] according to its position. But, in addition, the analysis of interactivity 
in relation to the heterogeneity of developing countries and the challenge of their characterization [8], comes up when the adoption of the theory of National Innovation Systems is offered as a useful perspective to renew the analysis of the development problem. On the other hand, the universality/ specificity contrast is an aspect that is clear when considering universities within a knowledge-producing system [9].

Similarly, the conception of innovative networks is proposed, taking into account the "translation function" and the "translator profile" as theoretical solutions that make visible the links that connect the main actors [10] and it has been argued that the flow The knowledge generated through these collaborations is very relevant both for the productive sectors and for universities and public research centers [11].

In this context, the Atlantic department regionally schematizes the Regional Innovation System - SRI, through the Departmental Council of Science and Technology -Codecyt, with the government department's dependency, under the coordination of the National System of Science Technology and Innovation - SNCTI, as a regionalization strategy of the Administrative Department of Science Technology and Innovation - Colciencias. This situation shows that the entity called to govern regional designs in the department is Codecyt, which requires strong development, which allows it to manage the information and knowledge derived from research and innovation.

For this reason, this article intends to guide research efforts towards the analysis of the exchanges and transactions visible through the networks of the university-\&- companies interrelation, so that the Interrelation Structures - EDI can be documented, of the Regional System of Local Innovation - SRI, in the department of Atlantic, in order to deliver tools that allow us to assume a more evident leadership in the regional field in Research and Development - R\&D. In this sense, it is proposed to address this issue, because the power of articulation of the EDI depends on its capacity for revitalization, so that the role of an interrelation structure, in general terms, would be to dynamize, in terms of technological innovation, the elements of certain environments, in addition to catalyzing and fostering the interrelationships between the elements of the SRI. This implies an imperative need to eliminate obstacles in relationships and to encourage agents, companies and research groups to actively participate in the innovative process, which motivates the implementation of Interrelation Structures - EDI.

\section{METHODOLOGY}

\section{SYSTEMIC APPROACH}

The absence or lack of availability of specific data, related to the institutional interactivity of the Regional Innovation System - SRI, of the Atlantic department, forced to incorporate in this investigation, explicitly, the systemic approach as a useful methodological tool to analyze the complexity of the interactions present in said system, which historically have been characterized by a scarce scientific implication. This methodology proposes to analyze the systemic aspects related to the evaluation of the contexts in which this system is built, the different modalities that they adopt and the type of resources that are exchanged in these processes. Thus, this research tries to advance in the analysis of the established indicators: 1) Mission and interrelation strategies; 2) the interrelation channels; 3) R\&D activities.

To achieve this, the analytical development of the research required a set of case studies and interviews, considering that the phenomenon of interactivity is a communicative phenomenon, whose most immediate area of reference is the university, as a place for creation and knowledge transmission. By having the exploratory data thrown by the environments, it is possible to intentionally select some major institutions, such as the academy and the productive sector, of the Regional Innovation System - SRI of the Atlantic, thus enabling the identification of innovative networks, attending to the "translation function" and the "profile of translators" as theoretical solutions that make visible the links that connect the main actors [10] and raised the instruments of information gathering.

\section{INTERRELATION STRUCTURES}

The interrelation is fundamental in the theory of systems, where the dynamics of the same in favor of the objective [7] are revealed. In this way the analysis is constructed with a set of exchanges between the elements of the system, such as projects that have involved formal and informal collaboration between the academy and the productive sectors - EU, which has aimed to mobilize scientific knowledge and / or technological for the solution of specific problems. The analysis considers quantitative information collected through both the direct interview and the application of a questionnaire to various actors participating in these projects. Analysis relevant to the systemic approach in identifying components, elements, relationships and their intrinsic information and communication flows, with clear objectives such as identifying interrelation structures, relevant for the increase of innovation rates in the region [12].

Under the approach, the analysis of elements that manifest or energize the Interrelation Structures -EDI, of the Regional Innovation System -SRI, of the department of Atlántico - Colombia, where statistics were used as a technique and the significance obtained by the Indicators: Mission and Strategies, Channels and R\&D Activities, after putting into practice the 
collection instruments referring to the Interrelation Structure indicators - EDI. The relevant relational referents are:

\section{A) Share information}

The study by this indicator, for the Mission and Strategies, presents key links such as scientific information, experiences of this type, methods, skills and data

\section{B) Interrelation channels}

This indicator shows the level of communication between the different participating subjects, a situation that encourages and strengthens the different interrelations. Similarly, show the most used means of communication and levels of trust.

\section{C) R\&D activities}

The reference to all the interrelationships between the different elements of the SRI and its relationship between the company and the academy, activities such as visits, stays and information exchange.

This analysis implies the need for an information system that connects companies with organizations and institutions dedicated to scientific and technological work (universities, research centers, consultancies, among others), a task that the State must carry out most of the time., thus being a transversal axis for the necessary conformation of relevant and effective innovative circuits, under the model scheme of an Innovation System, as shown in Figure 1.

Figure 1. Innovation Systems Model [1].

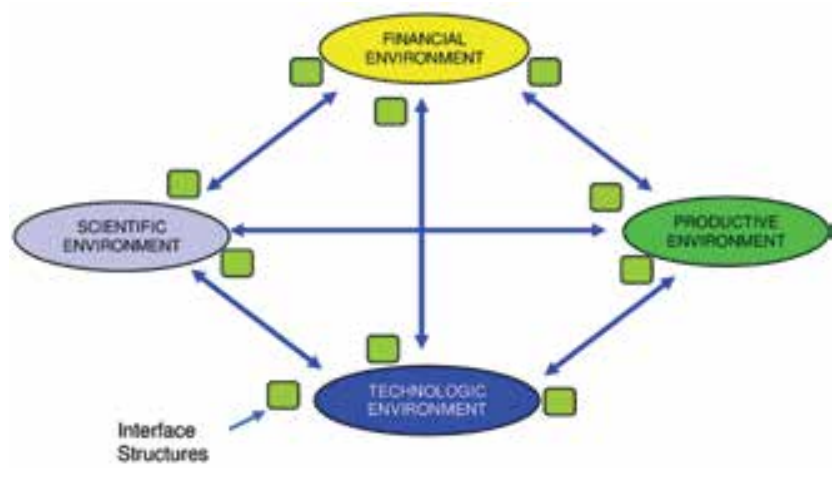

\section{RESULTS}

In this investigation, the elements that most flow in the interrelations between the actors or elements and components of SRI were identified, when they are involved in collaborative projects and types of resources that are exchanged; based on knowledge and slowly disaggregating it between information, knowledge and skills, where information is found at one end, tacit knowledge on the other and various levels of coded knowledge in between.
After the analysis of the results presented, the following resulting elements were established:

Figure 2. Share elements indicator.

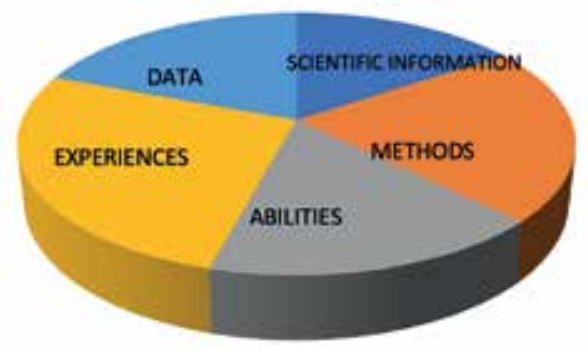

The study by indicator showed that the first one, related to the Mission and Strategies, as shown in Figure 2, presented a moderate level of scientific information, justified in the shortage of experiences of this type, methods, skills and data. Situation that contrasts with what was stated or stated, that it is key to share scientific information among the members of a certain system [10].

Figure 3. Interrelation Channel Indicator.

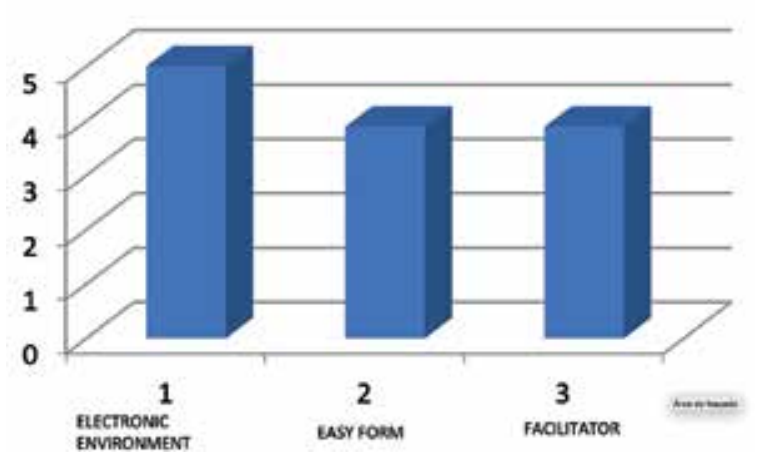

While in relation to the second indicator: Channels, it was placed in the medium level category, because the results showed an optimal level of communication between the different participating subjects, a situation that fosters and strengthens the different interrelations. Similarly, it was evidenced that the most used means of communication is electronic, a situation that for some actors is synonymous with distrust, which affects a greater weight, see figure 3 .

Finally, regarding the indicator: R\&D activities, referring to all the interrelations between the different elements of the SRI and its relationship between the company and the academy (activities such as: visits, stays and information exchange), shown in the figures 4, 5 and 6; This was in the category of moderate level, denoting a certain margin of distrust between the parties. 
Figure 4. Knowledge exchange indicator.

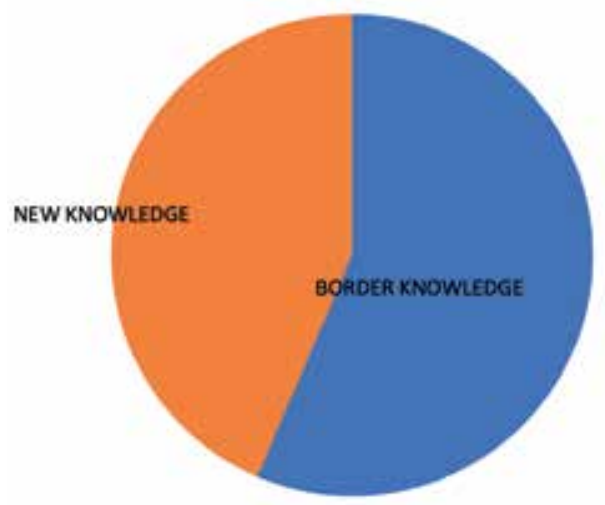

Figure 5. Indicator of R\&D Activities in the academy.

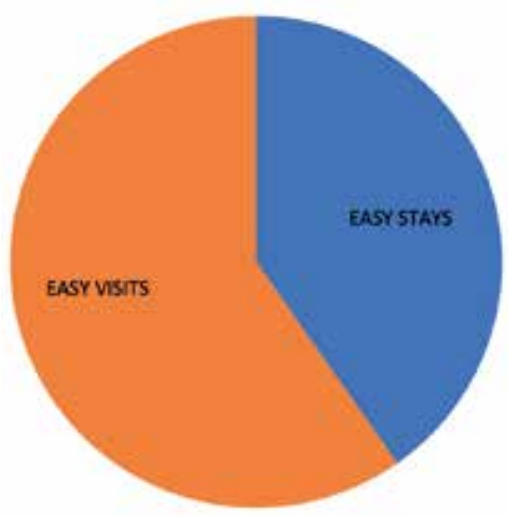

Figure 6. Indicator of R\&D Activities in companies.

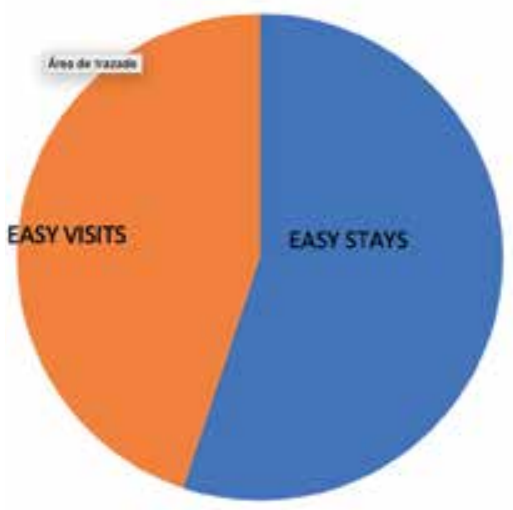

It is important for each of the components: that of its relational character, which expresses the necessary articulation of the actors for the success of the science, technology, innovation and development policies to be carried out. The components or Interrelation Structures or EDI are aspects that are relevant in the study of the processes of network construction between the academy, the productive sectors and the governments, or in other words between the public and private sectors, it is the knowledge that It is transferred, transmitted or exchanged and which become the basis on which optimizations are generated in products and / or processes, new technological developments are created, innovative activity is promoted and / or new knowledge is produced. That is, these processes of knowledge exchange and transfer through networks that have repercussions both in productive activities and in the generation of scientific and technological knowledge.

In order to establish the interrelation structure-EDI, of the Regional Innovation System -SRI, of the department of Atlántico - Colombia, where statistics were used as a technique and the significance obtained by the indicators was specified: Mission and Strategies, Channels and Activities of R\&D, after putting into practice the collection instruments referring to the Interrelation Structure - EDI indicators, a level of an arithmetic average of 3.92 and a moderate dispersion in the responses with a standard deviation of 0.06 were obtained. Next, Table 1 presents this measurement:

Table 1. Interrelation Structures.

\begin{tabular}{|c|c|c|c|c|c|c|c|c|c|c|c|c|}
\hline \multirow{3}{*}{\begin{tabular}{|l} 
Dimension: \\
Indicator
\end{tabular}} & \multicolumn{12}{|c|}{ Interrelation structure (EDI) } \\
\hline & \multicolumn{2}{|c|}{ TA (1) } & \multicolumn{2}{|c|}{ MA (2) } & \multicolumn{2}{|c|}{ NN (3) } & \multicolumn{2}{|c|}{ MD (4) } & \multicolumn{2}{|c|}{ TD (5) } & \multicolumn{2}{|c|}{ TOTAL } \\
\hline & $\begin{array}{l}\mathbf{F} \\
\mathbf{a}\end{array}$ & $\begin{array}{l}\text { Fr } \\
\%\end{array}$ & $\mathbf{F a}$ & $\begin{array}{l}\mathbf{F r} \\
\%\end{array}$ & Fa & $\begin{array}{l}\text { Fr } \\
\%\end{array}$ & Fa & $\begin{array}{l}\mathbf{F r} \\
\%\end{array}$ & $\mathbf{F a}$ & $\begin{array}{l}\mathbf{F r} \\
\%\end{array}$ & $\mathbf{F a}$ & $\mathbf{F r} \%$ \\
\hline \multirow{3}{*}{$\begin{array}{l}\text { Share } \\
\text { elements }\end{array}$} & 5 & $\begin{array}{l}28 \\
\%\end{array}$ & 8 & $\begin{array}{l}44 \\
\% \\
\end{array}$ & 0 & $0 \%$ & 2 & $8 \%$ & 3 & $\begin{array}{l}20 \\
\%\end{array}$ & \multirow{3}{*}{18} & \multirow{3}{*}{$100 \%$} \\
\hline & 0 & $0 \%$ & 3 & $\begin{array}{l}20 \\
\%\end{array}$ & 3 & $\begin{array}{l}20 \\
\%\end{array}$ & 10 & $\begin{array}{l}48 \\
\% \\
\end{array}$ & 2 & $\begin{array}{l}12 \\
\%\end{array}$ & & \\
\hline & 0 & $0 \%$ & 2 & $\begin{array}{l}16 \\
\%\end{array}$ & 4 & $\begin{array}{l}24 \\
\%\end{array}$ & 11 & $\begin{array}{l}52 \\
\%\end{array}$ & 1 & $8 \%$ & & \\
\hline Average & \multicolumn{6}{|c|}{3.61} & \multicolumn{6}{|c|}{ Medium level } \\
\hline $\begin{array}{l}\text { Standard } \\
\text { deviation }\end{array}$ & \multicolumn{6}{|c|}{0.16} & \multicolumn{6}{|c|}{ Moderate Dispersion } \\
\hline \multirow{3}{*}{ channels } & 1 & $\begin{array}{l}12 \\
\% \\
\end{array}$ & 2 & $\begin{array}{l}16 \\
\% \\
\end{array}$ & 5 & $\begin{array}{l}36 \\
\% \\
\end{array}$ & 6 & $\begin{array}{l}20 \\
\% \\
\end{array}$ & 4 & $\begin{array}{l}16 \\
\%\end{array}$ & \multirow{3}{*}{18} & \multirow{3}{*}{$100 \%$} \\
\hline & 1 & $8 \%$ & 3 & $\begin{array}{l}16 \\
\%\end{array}$ & 5 & $\begin{array}{l}24 \\
\%\end{array}$ & 7 & $\begin{array}{l}40 \\
\%\end{array}$ & 2 & $\begin{array}{l}12 \\
\%\end{array}$ & & \\
\hline & 1 & $4 \%$ & 2 & $8 \%$ & 3 & $\begin{array}{l}20 \\
\%\end{array}$ & 5 & $\begin{array}{l}28 \\
\% \\
\end{array}$ & 7 & $\begin{array}{l}40 \\
\%\end{array}$ & & \\
\hline Average & \multicolumn{6}{|c|}{4.25} & \multicolumn{6}{|c|}{ High level } \\
\hline $\begin{array}{l}\text { Standard } \\
\text { deviation }\end{array}$ & \multicolumn{6}{|c|}{0.18} & \multicolumn{6}{|c|}{ Moderate Dispersion } \\
\hline \multirow{3}{*}{$\begin{array}{c}\text { R\&D } \\
\text { Activitics }\end{array}$} & 0 & $0 \%$ & 2 & $\begin{array}{l}16 \\
\%\end{array}$ & 5 & $\begin{array}{l}28 \\
\%\end{array}$ & 3 & $\begin{array}{l}20 \\
\% \\
\end{array}$ & 8 & $\begin{array}{l}36 \\
\%\end{array}$ & \multirow{3}{*}{18} & \multirow{3}{*}{$100 \%$} \\
\hline & 1 & $4 \%$ & 2 & $8 \%$ & 5 & \begin{tabular}{|l|}
36 \\
$\%$ \\
\end{tabular} & 2 & $\begin{array}{l}12 \\
\% \\
\end{array}$ & 8 & $\begin{array}{l}40 \\
\%\end{array}$ & & \\
\hline & 0 & $0 \%$ & 2 & $\begin{array}{l}16 \\
\%\end{array}$ & 4 & $\begin{array}{l}20 \\
\%\end{array}$ & 4 & $\begin{array}{l}20 \\
\%\end{array}$ & 8 & $\begin{array}{l}44 \\
\%\end{array}$ & & \\
\hline Average & \multicolumn{6}{|c|}{3.90} & \multicolumn{6}{|c|}{ Medium level } \\
\hline $\begin{array}{l}\text { Standard } \\
\text { deviation }\end{array}$ & \multicolumn{6}{|c|}{0.28} & \multicolumn{6}{|c|}{ Moderate Dispersion } \\
\hline \multicolumn{13}{|c|}{ Average Dimension } \\
\hline Average & \multirow{2}{*}{\multicolumn{6}{|c|}{0.92}} & \multicolumn{6}{|c|}{ Medium level } \\
\hline $\begin{array}{l}\text { Standard } \\
\text { deviation }\end{array}$ & & & & & & & & Moc & derate & Disp & ersion & \\
\hline
\end{tabular}

Without proper coordination, each of the actors tends to disperse, which leads to the loss of growth opportunities for companies [3]. The ignorance of companies, for example, regarding entities with the capacity to provide them with ade- 
quate technological advice, to carry out applied research on issues related to their products, goes against their interests, so that the lack of information becomes a comparative disadvantage for the competitiveness and growth of companies as an interrelation structure.

This implies the need for an information system that connects companies with organizations and institutions dedicated to scientific and technological work (universities, research centers, consultancies, among others), a task that the State must sometimes perform, thus being a transversal axis for the necessary conformation of relevant and effective innovative circuits. Likewise, universities, which handle strong economic pressures as a result of the demand for massification, budget cuts and internal needs, require resources that, given the difficulties of the state budget, can only come from the private sector. From the relative weakness of each of the actors separately, there is a need for articulation and synergy, the "Sabbath triangle", as this policy of integration of actors and institutions that make up all SRIs is called in Latin America.

Additionally, it can be mentioned that there is an essential and often overlooked or ignored element of any SRI that claims to be successful: social capital; the representations of society about the value of science, technology and innovation that actively demand and intervene in the national system of science and technology, an element known as "social appropriation of knowledge."

\section{CONCLUSIONS}

It was determined that the interactivities of the elements of the SRI are moderated according to the environments sized in the region and immersed in the local context, however the relevant according to the methodology is EDI: type of knowledge that is exchanged and transferred, if coded or tacit, existing, new or border, disciplinary or interdisciplinary, importance of the areas of R\&D in companies for knowledge flows, regional knowledge spaces in exchanges and flows of networks, channels, mobility of personnel and the directionality of knowledge exchanges and the results of knowledge flows.

That is why they reflect a series of actions that can be objective in terms of the systemic analysis of the interactivity of the Regional Innovation System in the Department of the Atlantic: Institutionally strengthen the Regional Innovation System in the Department, which allows fostering scientific and technological activities based on the interaction capacity of the different actors of the system, encourage the promotion of departmental investment in Innovation and Development, establish strategies aimed at increasing the efficiency of departmental, public and private mecha- nisms (such as: support on a larger scale of the banking systems in terms of financing research and development projects to promote foreign investment, taking advantage of free trade agreements benefiting from having one of the ports with the greatest merchandise commercialization), investment in human capital ( by what is necessary to improve the quality of education at all levels by promoting adequate knowledge for technological learning and according to the needs of the market), consider providing support and strengthening to companies in the Department of the Atlantic (as it is it is necessary to create and implement actions and programs that lead to the technological and research development of this sector of small businesses, since they are an important part of our regional economic system), strengthen university-business-state relations, aimed at strengthening development processes scientific and technological in the department of the Atlantic, have more resources and sustainable for the financing of Science, Technology and Innovation, position the CT + I (Science, Technology and Innovation) as key activities for regional development, work in the evolution of territorial innovation systems is relevant to understand the nature of relations between government, business, and universities and research centers (changes in the conditions of global markets, the rapid evolution of the way knowledge is produced and disseminated, and the transformations in the models of productive specialization that occurred in the territories mean that SRIs can evolve, transform and modify some of their structural aspects), consolidate networks of actors, both social and make use of virtual social networks for the dissemination of information and activities among them, but above all, knowledge networks oriented to work areas and government programs aimed at the priority areas for scientific, technological and innovation development of the Department of the Atlantic.

In addition, it is proposed to look for organizational flexibility, public / private financing, to deploy a more effective information system among agents, reform of the education system with emphasis on natural and exact sciences, social capital formation policy (for example, using intensive and extensive ICT for the conformation of citizen support), strengthening of research networks (case of the genomics group of excellence).

\section{REFERENCES}

[1] Lundvall, Bengt-Åke. (2007). National Innovation Systems-Analytical Concept and Development Tool. Industry E Innovation. 14. 95-119. 10.1080/13662710601130863.

[2] W. Nelson y S. Winter, In search of a Useful Theory of Innovation, Research Policy, 6(1). p. 63. 1999.

[3] E. Castro and I. Fernández, "Innovacion y Sistemas de Innovación" 
2015. [Online]. Available: https://www.metaforum.es/. [Accessed: 06Jun-2019].

[4] I. Fernández, E. Castro, F. Conesa, A. Garcia. Las relaciones universidad-empresa: entre la transferencia de resultados y el aprendizaje regional. En: Revista Espacios. Vol. 21, №2. [Online]. Available: http:// www.revistaespacios.com/a00v2 ln02/62002102.html . [Accessed: 02-Feb-2019].

[5] J. Aguilar; O. Teran y L. Blanco. Sistema Regional de Innovación como mecanismo de gestión en Ciencia y Tecnología. Caso de estudio: Estado Mérida. Revista de Ciencias Sociales Available: http:/http:// ve.scielo.org/scielo.php. ISSN 1315-9518.. [online]. 2006, vol.12, n.3[Accessed: 02-Mar-2019]. pp. 439-453.

[6] S. Monroy, "Sistema Nacional de Ciencia, Tecnologia e Innovación" 2015. [Online]. Available: https:// comunidad.udistrital.edu.co/jruiz/ files/2015/02/sncti_vr_def_con_seguridad.pdf. [Accessed: 06-Oct2019].

[7] O. Bertoglio, "Introduccion a la Teoria General de Sistemas". Ed. Limusa. vol. 18, no. 167 , pp. 17-32. 2000.

[8] M.Admade y E. Romero, "Redes Innovativas Locales:Perspectiva comparada de tendencias metodologicas para el analisis". Universidad del Zulia, 2011. [Online]. Available: https://es.scribd.com/document/235515967/Admade-Paz-Maria-Teresa. [Accessed: 02-Abr2019].

[9] R. Arocena. y J. Sutz, "Sistemas de Innovacion y paises en desarrollo" Universidad de la Republica.2002. [Online]. Available: https://oei.es/. [Accessed: 02-May-2019].

[10] M. Luna, "Itinerarios del conocimiento: Formas dinámicas y contenidos-Un enfoque de redes". México, Universidad Nacional Autónoma de México.2003.

[11] R. Casas, "La formación de redes de conocimiento: una perspectiva regional desde México". México, Universidad Nacional Autónoma de México.2001.

[12] M. Alday y M. Cuenca, "Estructuras organizativas favorables a la innovación.”, Boletín de Estudios Económicos. LXIX. pp.477-493.2014. 